\title{
Editorial
}

\section{MEDICAL EDUCATION IN BANGLADESH PROBLEMS AND PROSPECTS}

\section{INTRODUCTION:}

The nature of medical education in Bangladesh is inherited from the then Pakistan. Although the task force set up in the year 2002 for updating new curriculum, promulgated in the academic year 20032004, it essentially remains the same for undergraduate medical education. About 20 in public sector and at the time of writing this paper about 38 medical colleges in private sectors conduct a five years course and offer MBBS degrees to more than 5000 students enrolled per year. The ratio of public to private sector graduates is almost 50:50. So far, medical education in Bangladesh is the shared responsibility of three different authoritiesministry of health, Bangladesh Medical and Dental Council (BM\&DC) and on the regional basis of existence any of the public Universities. Postgraduate courses are of varying durations from 2-5 years and are known as M.Phil, Ph.D, MCPS, FCPS, DO, DA, MD etc. All postgraduate courses which used to be conducted by the Public Universities are now controlled by the newly established Bangabandhu Sheikh Mujib Medical University (BSMMU).

\section{Historical Background:}

It is worth noting the transitions of medical education in Bangladesh from time to time. During British period the widely accepted medical degree was Licentiate in Medical Faculty (LMF) offered by several Medical Schools.

The Licentiate diploma was a course of 4 years durations. Increasing the durations from 4 years to 5 years, the diploma was replaced in phases, by MBBS degree.

Before the introduction of Postgraduate degrees of FCPS in Pakistan, UK based postgraduate degrees from Royal Colleges of UK were the only avenue for higher education in clinical subjects leading to MRCP in Medicine, FRCS in surgical sciences and MRCOG in Obstetrics and Gyne. Opportunities for higher studies in basic medical sciences were few and a far cry.
In early nineteen sixties the Pakistan College of Physicians and surgeons was established to offer FCPS. Later as sister Institute of Jinnah Postgraduate Medical Centre, Institute of Postgraduate Medicine and Research (IPGMR) started functioning in the then East Pakistan for promoting higher education in basic medical sciences leading to M.Phil degrees.

After the emergence of Bangladesh in 1971 Pakistan college of Physicians and Surgeons was reconstituted as Bangladesh College of Physicians and Surgeons (BCPS) and graduates are offered membership (MCPS) and fellowships (FCPS). Long after, IPGMR is reconstituted as Bangabandhu Sheikh Mujib Medical University (BSMMU). Before the advent of BSMMU the postgraduate degrees like MD and MS in different clinical subjects used to be conducted and controlled by most of the Public Universities in the country. Thus, since early 1980 MD and MS degree courses were conducted in the Public Universities including Dhaka side by side with Fellowship of BCPS. This type of dual systems did not bring any useful outcome. It gave rise to a great deal of confusion in consideration of appointment and promotion of candidates.

The universities were indifferent to make the nomenclature uniform for the postgraduate degree or even were not consistent in their methods of evaluations. This is not the case in the developed countries. As Bangabandhu Sheikh Mujib Medical University (BSMMU) has taken over conducting and controlling postgraduate courses, things are likely to change. Bangabandhu Sheikh Mujib Medical University (BSMMU) has concerned himself only with postgraduate education. However, for sometime in the post, its predecessor IPGMR started undergraduate Medical courses for MBBS as well as for Masters Degree in basic science subjects to meet the situation of dearth of teachers for which this country is in dire need. But soon it was abandoned for unknown reason. 


\section{A look at the Paramedical personal:}

Any sound health care delivery system, besides doctors and consultants need nurses, dentists, physiotherapists technologists etc. In a country with a population of 140 million we need a staggering number of these potential resource persons. There are few institutes for the scope of developing the manpower. Only recently B.Sc degree course has been introduced in laboratory medicine, dentistry and physiotherapy.

\section{Problems:}

The national objective of producing medically qualified persons has not been enunciated as yet.

(a) Whether our graduates are going to be community leader, a pivot in the primary health care system who should be adequately equipped with skill and knowledge to manage, guide and innovate health related problems in Primary health care systems for the teeming millions scattered in villages envisaged as Gonomukhi Swastha Babstha in fitting with the aspirations of the people of this country.

Or,

(b) Whether he is going to be a global citizen in the new world order competent to be a world class leader anywhere in the planet of earth and therefore, we should gear our medical education for international standard and international accreditation.

Or,

(c) Simply a commodity of export quality as skilled manpower for developing countries in Asia, Africa and the Middle East.

\section{Rationality:}

Medical education should be designed based on the enunciated national objectives.

The system in existence is taking us no where. In agreement with World Health Organization (WHO) concept it is known that the disease process takes its root in the socio-economic and environmental context. This country is different from that of a developed country and or countries with cold climates. But the system in which medical education is framed and taught has no difference from that of a most developed country. Even the diseases which are emphasized are diseases of the affluent and industrial nations. Tropical medicines are not emphasized. Once the clear national objective is enunciated then befitting that the health care delivery system is developed and the medical curriculum is made for studies and training adapting evidence-based medicine significantly different from laboratory-based medicine which can only be followed in the most technologically advanced country.

The Undergraduate Medical Education:-

At present the undergraduate medical curriculum is rigid, department driven, not clinically oriented and not even need based. Teaching strategies have not been even changed in the desired direction although the task force in 2002 modified the curriculum to produce good doctors with good foundations who should have the potential to become postgraduate doctor with proper exposure and training. The curriculum designed was accepted nationwide but in vain.

The introduction of community based teaching, formative assessment, integrated teaching, small group teaching, block posting, structured oral examination, objective structured practical examination, MCQ, SAQ in written examination are all aimed to produce competent doctors. But the methodologies of teaching remains largely didactic and teacher oriented and here comes the greatest challenge. Not even a single medical college in the country has adequate number of teachers.

There should be an appropriate balance between enrolment, size of the faculty, physical facilities, budget and total resources.

\section{Prospects:}

We are yet to get the fruit of the curriculum development done by the 1st task force. As medical education is a continuous process, an initiative has already been taken for modifications of the first curriculum with the aim of improving a number of aspects e.g time allotments to different subjects, phasing 2nd professional Examination, deleting formative assessment etc. In order to change medical education further there should not be a short cut. A long term plan is necessary for an appropriate need based medical education for the country.

\section{First we need to agree on several aspects:}

1. We have to enunciate the national objective(s) in unambiguous language. No mission without a goal is successful. To quote one medical educationist - it is a highly questionable practice to label someone as having achieved a goal when you don't even know what you 
would take as evidence of achievement.

2. Revamp the medical education on community based education and services (OBES)

3. Whether or not a single University Bangabandhu Sheikh Mujib Medical University (BSMMU) shall be the sole custodian to provide accreditation and conduct all activities related to examinations.

4. Should we have non-medically qualified teachers teaching in the medical colleges. Should Bangabandhu Sheikh Mujib Medical University (BSMMU) be allowed to re-introduce training of non-medical teachers in basic medical sciences such as Anatomy, Physiology, Biochemistry, Pathology, Microbiology, Pharmacology \& Therapeutics etc. The recent decision of Bangabandhu Sheikh Mujib Medical University (BSMMU) to give higher incentive to medically qualified basic science teachers in Anatomy, Physiology, and Biochemistry will go a long way in attracting medically qualified teachers in those disciplines

Without addressing the core problems, changing the methods in medical education is not likely to yield desired outcome.

\section{Prof. (Dr.) Hossain Reza}

Chairman

Editorial Board 